\title{
EVALUATION OF THE QUALITY OF LIFE OF PATIENTS SUBMITTED TO RENAL REPLACEMENT THERAPY: CROSS-SECTIONAL STUDY
}

\section{Tatiane Barbosa Soares Silva1, Liniker Scolfild Rodrigues da Silva*2, Jozivalda Venancio Caitano dos Santos ${ }^{3}$, Jéssiva Naylla de Melo Bezerra ${ }^{4}$, Aline Caroline Bezerra de Rebouças ${ }^{4}$, Sara Rebeca de Oliveira Lessa Mendes ${ }^{4}$, Genir Isidorio da Silva Santana ${ }^{5}$, Katyuscia Morais Barros ${ }^{6}$, Hugo Ricardo Torres da Silva ${ }^{7}$ and Givaneide Oliveira de Andrade Luz ${ }^{8}$}

\begin{abstract}
${ }^{1}$ Nurse, Specialist in Nephrology in the Residency modality from the Clinical Hospital (HC)/ Federal University of Pernambuco (UFPE). Recife, Pernambuco (PE), Brazil; ${ }^{2}$ Nurse, Specialist in Obstetric Nursing in the Residency modality from the Nossa Senhora das Graças College (FENSG)/University of Pernambuco (UPE). Public Health Officer from the Medical Sciences College (FCM)/UPE. Recife, Pernambuco (PE), Brazil; ${ }^{3}$ Nurse, Specialist in Women's Health in the Residency modality from the Clinical Hospital(HC)/Federal University of Pernambuco (UFPE). Recife, Pernambuco (PE), Brazil; ${ }^{4}$ Nurse, Specialist in Nephrology in the Residency modality from the Clinical Hospital (HC)/ Federal University of Pernambuco (UFPE). Recife, Pernambuco (PE), Brazil; ${ }^{5}$ Nurse, Specialist in Women's Health in the Residency modality from the Clinical Hospital (HC)/Federal University of Pernambuco (UFPE). Recife, Pernambuco (PE), Brazil; ${ }^{6}$ Nurse, Specialist in Nephrology in the Residency modality from the Clinical Hospital (HC)/ Federal University of Pernambuco (UFPE). Recife, Pernambuco (PE), Brazil; ${ }^{7}$ Doctor, Federal University of Campina Grande (UFCG). Campina Grande, Paraíba (PB), Brazil; ${ }^{8}$ Nurse, MSc in Nursing from the University of Pernambuco (UPE)/State University of Paraíba (UEPB). Recife, Pernambuco (PE), Brazil.
\end{abstract}

\section{ARTICLE INFO}

\section{Article History:}

Received $18^{\text {th }}$ June 2020

Received in revised form $20^{\text {th }}$ July 2020

Accepted $27^{\text {th }}$ August 2020

Published online $30^{\text {th }}$ September 2020

Key Words:

Quality of Life, Renal Dialysis, Renal Replacement Therapy, Sickness Impact Profile.

*Corresponding author: Liniker Scolfild Rodrigues da Silva

\begin{abstract}
Objective: To trace the epidemiological profile and evaluate the quality of life of patients undergoing replacement therapies, and whether there is a difference between these groups. Materials and Methods: This is a cross-sectional, descriptive, quantitative study conducted with 75 patients submitted to renal replacement therapies in a university hospital in the metropolitan region of Recife, of whom 42 were hemodialysis, 22 were peritoneal dialysis and 12 were transplanted, who agreed to participate in the research. Results: Regarding the profile of the modalities, the patients presented similarity only in terms of gender, income and place of residence, and the results obtained were female, income of one minimum wage and most lived in the metropolitan region of Recife/PE, respectively. Conclusion: In the comparison of quality of life with the therapies, in general, the transplanted ones obtained the best score; however, there was a significant influence on sociodemographic and clinical data on quality of life in various aspects, in the three modalities, evidencing that substitute therapies interfere in the quality of life of patients, causing difficulties in their daily lives regarding their family, social, mental, professional and leisure life.
\end{abstract}

Copyright (C) 2020, Tatiane Barbosa Soares Silva et al. This is an open access article distributed under the Creative Commons Attribution License, which permits unrestricted use, distribution, and reproduction in any medium, provided the original work is properly cited.

Citation: Tatiane Barbosa Soares Silva, Liniker Scolfild Rodrigues da Silva, Jozivalda Venancio Caitano dos Santos, Jéssiva Naylla de Melo Bezerra,

Aline Caroline Bezerra de Rebouças et al., 2020. "Evaluation of the quality of life of patients submitted to renal replacement therapy: cross-sectional study”, International Journal of Development Research, 10, (09), 40932-40938.

\section{INTRODUCTION}

Chronic Kidney Disease (CKD) consists of changes in the functionality and structure of the kidneys, and arises in a silent, progressive and irreversible manner, being measured by the glomerular filtration rate (GFR) for three continuous months, presenting $\mathrm{GFR}<60 \mathrm{ml} / \mathrm{min} / 1.73 \mathrm{~m}^{2}$, being classified into six stages classified by the GFR, with values varying from 90 to $\leq 15 \mathrm{ml} / \mathrm{min} / 1.73 \mathrm{~m}^{2}$.
In the latter two, upon presenting a GFR $\leq 29 \mathrm{ml} / \mathrm{min} / 1.73 \mathrm{~m}^{2}$, it is necessary to start renal replacement therapies (RRT) to assist in prolongation of life, which are hemodialysis (HD), peritoneal dialysis (PD) and kidney transplantation (TX) (Brazil, 2017). In Brazil, the total number of patients on chronic dialysis on July 1, 2017, was estimated at 126,583. This number indicates an increase of 3,758 patients $(3 \%)$ in a year. If we compare three 5-year periods, from 2002 to 2017, the average annual increase in the number of patients was 
4,960 from 2002 to 2007 (approximately 51\% in five years), 4,796 from 2007 to $2012(32.6 \%)$ and 5,799 from 2012 to 2017 (29.7\%). The most frequent primary causes of end-stage chronic kidney disease (CKD) in 2017 were hypertension (34\%) and diabetes (31\%) (Tomé et al., 2019). Therapies collaborate to improve health, but they do not represent the cure. One of the therapies is hemodialysis (HD), which performs blood purification through a semipermeable membrane connected to the dialysis machine, which removes the products from body metabolism through a dialyzer. The solution has its concentration similar to the physiological blood plasma, occurring exchanges between the blood and the dialysis solution.HD can be used in both acute and chronic forms of CKD (Carrillo Vega et al., 2017). In peritoneal dialysis (PD), the membrane in which the exchanges occur is the peritoneum, through diffusion, and the ultrafiltration product will be eliminated and drained through the fluid introduced into the abdominal cavity by a Tenckhoff catheter. Each exchange has an average duration of $30 \mathrm{~min}$ to 6 hours, composed of three cycles: infusion, permanence and drainage (Brazil, 2017). Transplantation (Tx) consists of the implantation of a healthy kidney in a CKD patient, whose kidney works inadequately. The kidney may be from a deceased or living person, and it aims to provide a normal renal physiological performance (Carrillo Vega et al., 2017).

These treatments change the routine of patients due to the time and procedures required by them, and end up leading to the development of physical, emotional, social, and food changes to the individual's life.Quality of life (QoL) in these patients has been one of the major health challenges, being defined by the World Health Organization (WHO) as the individual's understanding of the place he/she occupies, related to values according to their concerns, perspectives, goals and principles. Therefore, the importance of measuring it to assist professionals in the construction of care plans according to the needs of these patients (Luxardo et al., 2017). To assess QoL, some instruments were constructed such as Whoqol-Bref, with 26 questions, which evaluates the social, physical, psychological domains among others and whose score ranges from 0 to 100 points. Another questionnaire used is the SF-36 which can assess QoL in a generalized way, with ease of understanding and application, containing 11 questions, with scores ranging from 3 to 10 points each, with 9 domains, of which 8 will be classified individually and the overall condition in general (Pomeroy et al., 2020). Therefore, nursing plays a relevant role in assisting these patients seeking quality of life. Acting in educational practices in order to provide them with adequate knowledge for their self-care and involving the family in this process for strengthening the family bond. The analysis of the SF-36 results of each patient provides support for the elaboration of individual and collective care plans.

The nurse also provides the care of handling machines, catheters and arteriovenous fistulas, as providing assistance in complications before treatments (Silva and Mattos, 2019). The difficulties experienced by chronic renal patients when undergoing renal replacement therapies, their consequences in the most diverse areas of their lives, as well as in view of the importance of conducting studies aimed at this group, justified the performance of the present study. This study aimed to trace the epidemiological profile and evaluate the quality of life of patients submitted to renal replacement therapies, and whether there is a difference between these groups.

\section{MATERIALS AND METHODS}

This is a cross-sectional and descriptive study, with a quantitative approach, carried out in the nephrology unit composed of the Hemodialysis, Peritoneal Dialysis and infirmary room, and in the renal transplantation outpatient clinic of the Clinical Hospital of Pernambuco, public and reference in the nephrology area for the state of Pernambuco. For the development of this research, inclusion criteria applied were all patients from 18 years of age, female or male, followed-up by the CKD outpatient clinic and who underwent hemodialysis or peritoneal dialysis and those who underwent transplantation from December 2014 to December 2015. The exclusion criteria were patients followed-up at the nephrology outpatient clinic but undergoing hemodialysis and peritoneal dialysis in other hospitals, or those who performed these therapies eventually at the institution. Patients not registered in the nephrology outpatient clinic, and the transplanted from 2016 were also excluded. To perform data collection, two questionnaireswere used, one containing sociodemographic data and the other, clinical data, both constructed by the researcher, and the SF-36 (Medical Outcomes Study - Item Short-Form Health Survey 36), translated in Brazil in 1997 with the purpose of evaluating the quality of life to the treatment process.

The SF-36 contains 36 items that fully evaluate the individual, associated with scores for representation of each point evaluated, such as: physical, functional capacity, pain level, vitality, social, emotional and mental factors. The scores range from 0 to 100 points, and the higher the better QoL and the lower, the worse QoL (Klein et al., 2018). This questionnaire was chosen due to its easy application, understanding and time available for patients to answer during the performance of the therapies. The first two questions cover the general aspects of health; the following four are related to activities performed at work or daily life, the seventh and eighth evaluate the evolution of pain during treatment; the eighth and ninth analyze emotional and social factors, and the latter measures the disease health process (Klein et al., 2018). The research was performed at two different moments. Firstly, a survey of patients submitted to renal replacement therapies was performed in their respective sectors and, after that, both questionnaires were applied. The interviews were conducted during or before hemodialysis sessions; the evaluations in the peritoneal dialysis occurred during the outpatient call on Wednesdays and the transplantation was performed in the renal Tx outpatient clinic after consultations. For data analysis, a database was created in the EPI INFO program, version 3.5.2, with double entry, which was exported to the software Statistical Package for the Social Sciences SPSS, version 18. To evaluate the socioeconomic and clinical profile of the patients evaluated, the percentage frequencies were calculated and the distributions by RRT group were constructed. The comparison of the profile of patients on hemodialysis, peritoneal dialysis and transplantation was performed by chisquare test.

In the evaluation of the patients' quality of life scores, the mean and standard deviation were calculated. The quality of life was estimated in a RRT modality group and SF-36 domain. The evaluation of the normality of the score was performed by the Kolmogorov-Smirnov test.In cases where normality was indicated, the comparison of the quality of life score between the different modalities of RRT was made with 
the application of the ANOVA test, and in cases whose normality was not indicated, the Kruskal-Wallis test was applied.To evaluate the influence of the personal profile and clinical profile of the quality of life scores of these patients, the Student's t-test was included to compare the means between two groups, when the indication of normality was observed, and the Mann-Whitney test for comparison of the quality of life score between two groups, when the indication of the normality of the score was not observed. The 5\% significance level was considered.

\section{RESULTS}

The sample of this study was composed of 77 patients distributed in the three modalities of renal replacement therapies (RRT), 43 in HD, 22 in PD and 12 in Renal Tx, and each group presented different profiles regarding its variables, with the loss of three patients who did not agree to participate in the research. in the age group, because patients on hemodialysis obtained equal values in the three categories as described in Table 1, while peritoneal dialysis was between 40 and 59 years and those who underwent transplantation were 17 to 39 years old. Regarding ethnicity, black and brown were dominant in the HD group, in PD, white had the highest numbers and in transplant recipients, white and brown predominated. Even though different distributions are found in the groups evaluated, the Chi-square homogeneity test was significant in the following factors: age ( $p$-value $<0.001)$, marital condition $(\mathrm{p}$-value $=0.048)$, educational level $(\mathrm{p}$-value $=0.001)$, professional condition ( $\mathrm{p}$-value $=0.022$ ) and place of residence $(p$-value $=0.013)$, indicating that the profile of patients about these factors are different among the RRT modality. The prevalence of SAH was high in the three groups and in relation to the access used in RRT, there was a predominance of arteriovenous fistula (AVF) in hemodialysis, the Tenckhoff catheter was used by all patients on peritoneal dialysis because this access is adequate for therapy.

Table 1. Distribution of the socioeconomic profile of the patients evaluated, according to the RRT modality. Recife, Pernambuco (PE), Brazil, 2016

\begin{tabular}{|c|c|c|c|c|c|c|}
\hline \multirow[t]{3}{*}{ Assessed factor } & \multicolumn{6}{|c|}{ RRT Modality } \\
\hline & \multicolumn{2}{|c|}{ Hemodialysis } & \multicolumn{2}{|c|}{ Peritoneal Dialysis } & \multicolumn{2}{|c|}{ Transplantation } \\
\hline & $\mathrm{n}$ & $\%$ & & $\%$ & $\mathrm{n}$ & $\%$ \\
\hline \multicolumn{7}{|l|}{ Sex } \\
\hline Male & 15 & 34.9 & 7 & 31.8 & 5 & 41.7 \\
\hline Female & 28 & 65.1 & 15 & 68.2 & 7 & 58.3 \\
\hline \multicolumn{7}{|l|}{ Age } \\
\hline $17-39$ years & 14 & 33.3 & 0 & 0.0 & 7 & 63.6 \\
\hline $40-59$ years & 14 & 33.3 & 14 & 63.6 & 4 & 36.4 \\
\hline 60 or more & 14 & 33.3 & 8 & 36.4 & 0 & 0.0 \\
\hline Minimum-Maximum & \multicolumn{2}{|c|}{$17-88$} & \multicolumn{2}{|c|}{$44-82$} & \multicolumn{2}{|c|}{$21-54$} \\
\hline Mean \pm Standard deviation & \multicolumn{2}{|c|}{$48.8 \pm 17.8$} & \multicolumn{2}{|c|}{$56.4 \pm 11.4$} & \multicolumn{2}{|c|}{$36.1 \pm 11.4$} \\
\hline \multicolumn{7}{|l|}{ Ethnicity } \\
\hline Brown & 15 & 34.9 & 5 & 22.7 & 5 & 41.7 \\
\hline White & 11 & 25.6 & 9 & 41.0 & 5 & 41.7 \\
\hline Black & 15 & 34.9 & 7 & 31.8 & 2 & 16.6 \\
\hline Other & 2 & 4.6 & 1 & 4.5 & 0 & 0.0 \\
\hline \multicolumn{7}{|l|}{ Marital status } \\
\hline Unmarried & 22 & 51.2 & 5 & 22.7 & 9 & 75.0 \\
\hline Married & 17 & 39.5 & 13 & 59.1 & 3 & 25.0 \\
\hline Widow(er) & 3 & 7.0 & 4 & 18.2 & 0 & 0.0 \\
\hline Divorced & 1 & 2.3 & 0 & 0.0 & 0 & 0.0 \\
\hline \multicolumn{7}{|l|}{ Schooling } \\
\hline Illiterate & 5 & 11.6 & 2 & 9.1 & 1 & 9.0 \\
\hline Comp/incompl primary education & 21 & 48.8 & 14 & 63.6 & 0 & 0.0 \\
\hline Comp/incompl secondary education & 15 & 34.9 & 4 & 18.2 & 5 & 45.5 \\
\hline Comp/incompl higher education & 2 & 4.7 & 2 & 9.1 & 5 & 45.5 \\
\hline \multicolumn{7}{|l|}{ Religion } \\
\hline Catholic & 22 & 53.7 & 11 & 57.9 & 4 & 36.3 \\
\hline Evangelical & 16 & 39.0 & 7 & 36.8 & 5 & 45.5 \\
\hline Spiritist & 1 & 2.4 & 1 & 5.3 & 1 & 9.1 \\
\hline Others & 2 & 4.9 & 0 & 0.0 & 1 & 9.1 \\
\hline \multicolumn{7}{|l|}{ Income } \\
\hline Up to 1 Minimum wage & 22 & 51.2 & 15 & 68.2 & 7 & 58.4 \\
\hline 2 - 3 Minimum wages & 19 & 44.2 & 6 & 27.3 & 4 & 33.3 \\
\hline 4 or more Minimum wages & 2 & 4.6 & 1 & 4.5 & 1 & 8.3 \\
\hline \multicolumn{7}{|l|}{ Place of residence } \\
\hline Recife and metropolitan area & 39 & 90.7 & 14 & 63.6 & 7 & 63.6 \\
\hline Countryside & 4 & 9.3 & 8 & 36.4 & 4 & 36.4 \\
\hline \multicolumn{7}{|l|}{ Water treatment } \\
\hline Treated & 41 & 95.3 & 22 & 100.0 & 12 & 100.0 \\
\hline Not treated & 2 & 4.7 & 0 & 0.0 & 0 & 0.0 \\
\hline
\end{tabular}

Concerning the socioeconomic profile of patients submitted to RRT, some similarities were identified between them, showing that the female gender prevailed, the level of education was incomplete/complete primary school, most lived in the metropolitan region of Recife, had an average income of one minimum wage. On the other hand, the differences found were
Regarding the time of treatment, most had less than 1 year in hemodialysis treatment, and those submitted to PD and transplantation had a prevalence of 2 and 5 years in treatment. Table 2 shows significant values in the variable type of access for RRT ( $p$-value $<0.001$ ), indicating that the accesses used differ between the RRT modalities. 
Table 2. Distribution of the clinical profile of the patients evaluated, according to the RRT modality. Recife, Pernambuco (PE), Brazil, 2016

\begin{tabular}{|c|c|c|c|c|c|c|}
\hline \multirow[t]{3}{*}{ Assessed factor } & \multicolumn{6}{|c|}{ RRT Modality } \\
\hline & \multicolumn{2}{|c|}{ Hemodialysis } & \multicolumn{2}{|c|}{ Peritoneal Dialysis } & \multicolumn{2}{|c|}{ Transplantation } \\
\hline & $\mathrm{n}$ & $\%$ & $\mathrm{n}$ & $\%$ & $\mathrm{n}$ & $\%$ \\
\hline \multicolumn{7}{|l|}{ Comorbidities } \\
\hline Arterial hypertension & 30 & 52.6 & 19 & 55.9 & 5 & 55.6 \\
\hline Diabetes mellitus & 10 & 17.5 & 6 & 17.6 & 1 & 11.1 \\
\hline Lupus & 5 & 8.8 & 4 & 11.8 & 0 & 0.0 \\
\hline Hepatitis C & 0 & 0.0 & 0 & 0.0 & 1 & 11.1 \\
\hline Others & 12 & 21.1 & 5 & 14.7 & 2 & 22.2 \\
\hline \multicolumn{7}{|l|}{ RRT access } \\
\hline No access use & 0 & 0.0 & 0 & 0.0 & 12 & 100.0 \\
\hline Catheter & 9 & 21.4 & 0 & 0.0 & 0 & 0.0 \\
\hline Permcath & 15 & 35.7 & 0 & 0.0 & 0 & 0.0 \\
\hline Arteriovenous fistula & 18 & 42.9 & 0 & 0.0 & 0 & 0.0 \\
\hline Tenckhoff ca.t & 0 & 0.0 & 22 & 100.0 & 0 & 0.0 \\
\hline \multicolumn{7}{|l|}{ Treatment length } \\
\hline Less than 1 year & 19 & 45.2 & 1 & 4.5 & 1 & 8.3 \\
\hline 1 to less than 2 years & 4 & 9.5 & 3 & 13.6 & 2 & 16.7 \\
\hline $2-5$ years & 6 & 14.3 & 8 & 36.4 & 8 & 66.7 \\
\hline $6-10$ years & 6 & 14.3 & 6 & 27.3 & 0 & 0.0 \\
\hline Over 10 years & 7 & 16.7 & 4 & 18.2 & 1 & 8.3 \\
\hline
\end{tabular}

${ }^{1} \mathrm{p}$-value of the Chi-square test for homogeneity (If $\mathrm{p}$-value $<0.05$ ).

Source: Created by the authors.

Table 3. Analysis (mean \pm standard deviation) of the quality of life of patients evaluated according to the domains. 2016 Recife, PE

\begin{tabular}{lcccc}
\hline Assess domain & \multicolumn{3}{c}{ RRT Modality } & p-value \\
\cline { 2 - 4 } & Hemodialysis & Peritoneal Dialysis & Transplantation & \\
\hline Functional capacity & $46.2 \pm 34.8$ & $41.4 \pm 32.4$ & $79.2 \pm 21.7$ & $0.004^{1}$ \\
Limitation by physical aspects & $22.7 \pm 36.9$ & $22.7 \pm 36.9$ & $70.8 \pm 41.1$ & $0.002^{2}$ \\
Pain & $74.8 \pm 29.1$ & $60.1 \pm 31.9$ & $68.0 \pm 39.2$ & $0.201^{2}$ \\
Overall health condition & $51.5 \pm 25.2$ & $44.0 \pm 27.0$ & $62.8 \pm 29.4$ & $0.146^{1}$ \\
Vitality & $50.6 \pm 26.6$ & $58.4 \pm 27.3$ & $70.4 \pm 28.4$ & $0.077^{1}$ \\
Social aspects & $70.1 \pm 30.1$ & $69.3 \pm 28.8$ & $82.3 \pm 31.3$ & $0.269^{2}$ \\
Limitation by emotional aspects & $48.1 \pm 45.6$ & $50.0 \pm 44.5$ & $61.1 \pm 42.2$ & $0.725^{2}$ \\
Mental health & $68.9 \pm 26.3$ & $67.1 \pm 28.3$ & $73.3 \pm 28.3$ & $0.814^{1}$ \\
\hline 1p-value of the ANOVA test (if $\mathrm{p}$-value $<0){ }^{2}{ }^{2} \mathrm{p}-$-value of the Kruskall-Wallis test. & & \\
\hline
\end{tabular}

${ }^{1} \mathrm{p}$-value of the ANOVA test (if p-value $<0$ ), ${ }^{2}$ p-value of the Kruskall-Wallis test.

Source: Created by the authors.

In the description of the quality of life of patients according to the domains of the SF-36 and the RRT modality, table 3 shows that, on average, patients submitted to transplantation presented higher quality of life score in the domains: Functional capacity, Limitation by physical aspects, Overallhealth condition, Vitality, Social aspects, Limitation by emotional aspects and Mental health, except in the Pain domain, because patients on hemodialysis obtained a higher score in quality of life. Despite the prevalence in transplanted patients, the test was significant only in the functional capacity and limitation by physical aspects domains, indicating a similarity in the other groups. Upon analyzing the influence of the personal profile on the quality of life of patients undergoing replacement therapies. In the group of patients undergoing hemodialysis, the only factor that presented a significant influence on quality of life was the place of residence, and this factor influences relevantly only the Pain domain ( $p$-value $=0.035$ ). Furthermore, the quality of life scores in this domain are higher in patients living in the countryside. In the distribution of quality of life according to the domains and the clinical profile of HD patients regarding the Overall health condition, the only different factor in patient's quality of life is the use of AVF (mean $=60.8$, pvalue $=0.040$ ).For the domains Limitation by emotional aspects and Mental health, there was a significant influence of the use of AVF on quality of life (p-value $=0.043$ and 0.021 , respectively). Furthermore, the group that used the AVF presented the highest mean score.
In the group submitted to peritoneal dialysis, the variables of the socioeconomic profile that presented differences in QoL were race, marital condition and schooling. The race influenced the domain Overall health condition ( $\mathrm{p}$-value = 0.001 ) and Mental Health (p-value $=0.009)$, in which the white group obtained a higher mean for QoL in these domains (mean $=66.8$ and 84.0, respectively). Furthermore, the patient's schooling not only influenced the QoL ( $p$-value = 0.049 ), but there was also a directly proportional relationship between increasing age and QoL. In addition, the group with higher education obtained the highest mean score in this domain $($ mean $=82.5)$.

Moreover, regarding the interference of clinical variables in the QoL domains, patients undertreatment for over 10 years also presented a different mean in the group higher than patients undergoing treatment for less time. In the group submitted to transplantation, the variables of socioeconomic profile that had differences in this group in QoL were age and marital condition. Age obtained higher scores in the pain ( $\mathrm{p}$ value $=0.007)$, Overall health condition $(p$-value $=0.019)$, Vitality $(p$-value $=0.037)$ and Mental health $(p$-value $=0.043)$ domains. In this group, the age group between 17 and 39 years presented a better score for QoL. Regarding marital condition, there was a significant difference for the domains: Overall health condition $(p$-value $=0.043)$, Vitality $(p$-value $=0.050)$ and Mental health $(\mathrm{p}$-value $=0.041)$. 


\section{DISCUSSION}

Concerning the relationship between the domains of the SF-36 questionnaire and the sociodemographic data, there were differences in the HD group only in the Pain domain (p-value $=0.035$ ), being influenced by the place of residence, demonstrating that people living in the countryside feel less pain. This pain reported by patients can usually be related to musculoskeletal complications developed over long years of treatments, fistula punctures, catheters and manipulation, as well as the position during HD and its length (Melo et al., 2019; Peipert et al., 2019). This pain may be interfered by the displacement from the residence to the place of treatment, upon traveling long hours, in a transport without comfort, moving through damaged roads, which makes the route more difficult for patients living in the countryside, according to the literature (Gesualdo et al., 2017; Bai et al., 2019). However, there was no justification for the relationship between these two aspects in the literature to explain a better QoL; the possible fact is that patients living in the countryside present a higher pain threshold since many work with manual activities in the rural environment, such as hoe handling and care for crops, at the fair carrying weight. In the clinical data, the present article found a significance of the AVF on the QoL domains, in which patients with AVF contributed to a better quality of life in the domains of overallcondition, emotional aspects and mental health. This is because AVF causes less discomfort than catheters, few alterations and complications to patients, because those who use the catheter need care, such as: not sleeping on the catheter in order not to bend it, impairing the flow of dialysis; do not wet the dressing during the bath, in order to avoid a higher risk of infection, unlike AVF, which brings greater safety to treatment, more convenience and better quality of life, being preferred by patients.Therefore, it is believed to provide a better coping, comfort and tranquility to the patient during treatment, favoring improvements in these domains found (Bettoni et al., 2017; Natale et al., 2019).

Among the replacement therapies, in this research, hemodialysis had the highest rates in relation to the utilization rate, understood several times that its discovery takes place unexpectedly, requiring an urgent dialysis treatment. In these situations, hemodialysis (HD) is the therapy that best meets this need, also requiring the installation of an immediate access called temporary catheter.The number of patients starting dialysis treatment in Brazil has been growing in recent years, reaching approximately 126,000 people in 2017 (Brazil, 2017). In the peritoneal dialysis group, the white color influenced QoL in the parameters of mental health and overall condition. Although this association is not well established, it is important to highlight the positive result that these scores represent in the lives of these patients, as the overall condition domain establishes a comparison between the past year and the existing improvements in the current period, reflecting in good results,demonstrating a good adaptation of the patient and therapy over the years with stability of the clinical picture, achieving significant improvement in health and positively favoring the patient's view of his/herQoL. The mental health domain measures mood condition and patient satisfaction regarding the disease, favoring adequate coping; both domains have relevant characteristics because they evaluate parameters essential to patients' lives, reflecting on QoL (Carrillo Veja et al., 2017).
There was a relationship between QoL and patients' schooling, where those with higher education obtained better scores, because the longer the study time, the better the understanding of the team's guidelines. This relationship can be reaffirmed in a research conducted with CKD patients, evidencing that inadequate attitude and knowledge interfere in their selfcare.Therefore, the team's performance is important, because it is based on health education, to help them to assume their responsibility for their self-care and to increase their adherence to therapy, bringing benefits to their health, as well as assist in emotional, family support and prevention of infections (Bettoni et al., 2017). Therefore, the higher the degree of study and understanding, the better the quality of life. This research also revealed that patients with more than 10 years of treatment had a better QoL index, when compared to those with a few years of treatment, a fact that may result from a better adaptation to therapy and the balance of the clinical picture by adequate treatment, favoring an ideal QoL (Silva and Mattos, 2019). In the overall quality of life (QoL), upon comparing the three modalities with the SF-36 domains, transplanted patients obtained the best results in almost all domains, except pain domains. This information was evidenced in another article, showing that all QoL domains had results above $50 \%$, with all reflecting the changes established by transplantation in the patients' lives, because they allow an independence of the machine, the limitation of leisure schedules due to therapy being performed three times a week, the food restriction, the impossibility of working, complications for travel, among others (Melo et al., 2019). Nevertheless, the functional capacity and physical aspects domains were the ones with the highest scores. It is believed to be related to the fact that transplantation favors the return to physical activities, a healthier and more complete diet, the reduction of pain and physical limitations imposed by the treatment.A research identified the importance of physical activity to improve physical and mental health and control comorbidities, reducing the risk and promoting QoL (Liao et al., 2019; Tomé et al., 2019).

In this study, significance values were detected in age and marital condition on QoL domains, including: overall condition, vitality, mental health and pain.The age group from 17 to 39 years interfered in QoL in the areas of pain, overall condition, vitality and mental health, and this range is characterized by suffering less influence from chronic diseases and physical aspects, due to the characteristic of age itself, decreasing over the years, further deteriorating with the impact of CKD on the lives of these patients over time.A similar result was identified in a study, finding that $68 \%$ of transplant recipients were between 18 and 35 years old, stressing a concern about the drop in productivity of this range, due to the limitations exposed by the treatment itself, noting that they will have to take immunosuppressant permanently and will have some physical limitations, because they cannot pick up weight after kidney implantation (Luxardo et al. , 2018; Saeed et al., 2019). Regarding the influence of age on the overallQoL evidenced in this article, younger people have better physical conditioning and a faster recovery, and, when associated with transplantation, it will provide the absence of fatigue, sleep alteration, impaired locomotion related to femoral access punctures, machine dependence and pain, contributing to improving patients' perception of their overall condition.However, in the evaluated articles, there were no associations between these aforementioned factors. One study showed that QoL depends on the age to have better scores, and 
the maximal age to achieve them is 30 years (Salim et al., 2019; Silva and Mattos, 2019; van Sandwijk et al., 2019). In relation to the pain domain, in the current research, younger patients present less pain, and can be explained by a study that identifies that, after transplantation, there is a significant organic improvement, in addition to the fact that this treatment decreases the number of invasive procedures and avoids the development of pain due to the various complications related to long hemodialysis treatments (Melo et al., 2019; Shih et al., 2019). As for vitality, the research brought an improvement in QoL due to age. This fact can be clarified, in transplant recipients, by the literature, because they feel more vigorous, feeling more strength and will at some times throughout therapy. All this under interference influenced by physical health, since, when they were submitted to hemodialysis and peritoneal dialysis, they were physically compromised after the therapies, feeling tired, hypotension, malaise, cramps, even preventing them from performing some daily life activities, being minimized after transplantation, favoring the restoration of overall health (Klein et al., 2018; Voskamp et al., 2019; Kirkman et al., 2019).

Regarding mental health, high QoL scores were evidenced in patients undergoing transplantation. These data were proven by several studies that also showed high rates in this variable related to quality of life after surgery. One of these describes the feelings of patients after the procedure, who report feelings of happiness, calm and tranquility, because they do not need to return for hemodialysis. Nonetheless, one may suggest intervention in this area of social relations, because dialysis treatment has a routine of restricting family and social life, modifying family life between patients and family members, also reducing leisure time due to the routine imposed by dialysis therapy. This makes many sad, depressed and discouraged, interfering with their emotions. When they perform the transplant, these feelings are replaced by relief and hope. Therefore, with these changes in their lives, patients achieve a better quality of life.

\section{Conclusion}

Despite the difficulties and particularities inherent to the treatments, some factors contributed to favor a better quality of life for patients. In hemodialysis patients, the variable place of residence and arteriovenous fistula favored a better QoL for this group. In those who underwent peritoneal dialysis, race, marital condition, schooling and treatment time positively influenced, obtaining better scores in overallcondition, functional capacity and mental health. Transplant recipients had the best quality of life among the three therapies, justified by the fact that therapy provides greater independence to patients regarding self-care, physical and leisure, enabling the return to work and normal activities of daily life, a better life expectancy and, thus, the increase in the degree of satisfaction, favoring a better quality of life.The domains with the most significant results were pain, vitality and mental health in transplant recipients. This study, upon evaluating the quality of life of patients in renal replacement therapies and which factors interfere with it, will help professionals who deal with this public better understand their needs, seeking the best way to help them in the construction of a therapeutic plan appropriate to the needs of each group so that they can improve the quality of life of these patients.As well as they can subsidize the outpatient service in the planning of individual and collective goals and care plans for this clientele. However, there was a scarcity in the literature regarding the relationship between the domains of the SF36 and the sociodemographic and clinical data, hindering supporting some variables, thus requiring further studies focused on the theme involving the three modalities in the same research.

\section{REFERENCES}

Bai YL, Chang YY, Chiou CP, Lee BO (2019). Mediatingeffectsof fatigue ontherelationships among sociodemographic characteristics, depression, andquality of life in patients receiving hemodialysis. Nurs Health Sci. 21:231- 238. https://doi.org/10.1111/nhs.12587

Bettoni LC, Ottaviani AC, Orlandi FS (2017). Associação entre o autocuidado e a qualidade de vida de pacientes com doença renal crônica. Revista Eletrônica De Enfermagem, 19. https://doi.org/10.5216/ree.v19.27442

Brasil (2017). Ministério Da Saúde. Protocolo Clínico e DiretrizesTerapêuticas Anemia na Doença Renal Crônica. Portaria No 365, De 15 De Fevereiro De 2017. Portarias da Secretaria De Atenção À Saúde. p.1-25.

Carrillo Vega MF, Pelcastre Villafuerte BE, Salinas Escudero G, Durán Arenas L, López Cervantes M (2017). Empoderamiento y apoyo social en pacientes conenfermedad renal crónica: estudio de caso enMichoacán, Mexico. Rev Panam Salud Publica; 41: e164. https://doi.org/10.26633/RPSP.2017.164

Gesualdo GD, Duarte JG, Zazzetta MS, Kusumota L,Say KG, Pavarini SCI, Orlandi FS (2017). Cognitive impairment of patients with chronic renal disease on hemodialysis and its relationship with sociodemographic and clinical characteristics. Dementia \& Neuropsychologia, 11(3), 221-226. https://doi.org/10.1590/1980-57642016dn11030003

Kirkman DL, Scott M, Kidd J, Macdonald JJ (2019). The effects of intradialy ticexerciseon hemodialysis adequacy: A systematic review. Semin Dial. 32:368-378. https://doi.org/10.1111/sdi.12785

Klein SK, Fofonka A, Hirdes A, JacobMHVM (2018). Qualidade de vida e níveis de atividade física de moradores de residências terapêuticas do sul do Brasil. Ciência \& Saúde Coletiva, 23(5), 1521-1530. https://dx.doi.org/10.1590/1413-81232018235.13432016

Liao JL, van den Broek $\square$ Best O, Smyth B, Hong D, Vo K, Zuo L, Gray NA, Chan CT, de ZoysaJ., Perkovic V, Jiang L, Jardine M (2019). Effect ofextended hours dialysisonsleep quality in a randomizedtrial. Nephrology, 24: 430-437. doi:10.1111/nep.13236

Luxardo R, Kramer A, González-Bedat MC, Massy ZA, Jager KJ, Rosa-Diez G, Noordzij M (2018).Theepidemiologyof renal replacementtherapy in twodifferentpartsofthe world: the Latin American Dialysis and Transplant Registry versus the European Renal Association-European Dialysis and Transplant Association Registry. Rev Panam Salud Publica.42:e87. https://doi.org/10.26633/RPSP.2018.87

Melo GAA, Aguiar LL, Silva RA, Quirino GS,PinheiroAKB, Caetano JÁ (2019).Factorsrelatedtoimpairedcomfort in chronickidneydiseasepatientsonhemodialysis. Revista Brasileira de Enfermagem, 72(4), 889-895. Epub 19 de agosto de 2019.https://dx.doi.org/10.1590/0034-71672018-0120

Natale P, Palmer SC, Ruospo M, Saglimbene VM, Rabindranath KS, Strippoli GFM (2019). Psychosocial interventions for preventing and treating depression in dialysispatients. Cochrane Database of Systematic 
Reviews,12:CD004542.

https://dx.doi.org/10.1002/14651858.CD004542.pub3.

Peipert JD, Nair D, KlickoK,Schatell DR, Hays RD (2019). Kidney Disease Qualityof Life 36-Item Short FormSurvey (KDQOL-36) NormativeValues for The United States Dialysis Population and New Single Summary Score. J Am Soc Nephrol 30: 654-663, 2019. doi: https://doi.org/10.1681/ASN.2018100994

Pomeroy IM, Tennant A., Mills RJ, Young CA (2020). The WHOQOL-BREF: a modernpsychometricevaluationof its internalconstructvalidity in peoplewithmultiplesclerosis. Qual Life Res. 29:1961-1972. https://doi.org/10.1007/ s11136-020-02463-Z

Saeed F, Sardar MA, Davidson SN, Murad H, Duberstein PR, Quill TE (2019).Patients' perspectives ondialysisdecisionmaking andend-of-lifecare. 91: 294-300. https://doi.org/10.5414/CN109608.

Salim, SA, Zsom, G, Cheungpasitporn, W, Fülöp, T (2019). Benefits, challenges, and opportunities using home hemodialys is with a focuson Mississippi, a rural southernstate. Semin Dial. 32:80-84. https://doi.org/10.1111/sdi.12751

Shih CY, Huang CY, Huang ML, Chen CM, Lin CC, Tang FI (2019). The association of sociodemographic factors and needs of haemodialysis patients according to Maslow's hierarchy of needs. J ClinNurs. 28:270- 278. https://doi.org/ 10.1111/jocn.14532
Silva PEBB, Mattos M (2019).Conhecimentos da equipe de enfermagem no cuidado intensivo a pacientesem hemodiálise. Journal Health NPEPS. 4(1):200209.http://dx.doi.org/10.30681/252610103297

Thomé FS, Sesso RC, Lopes AA, LugonJR, MartinsCT (2019). Inquérito Brasileiro de Diálise Crônica 2017. Brazilian Journal of Nephrology,41(2), 208-214. EpubMarch 28, 2019. https://doi.org/10.1590/2175-8239jbn-2018-0178

van Sandwijk MS, Al Arashi D, van de Hare FM, van der Torren JMR, Kersten MJ, Bijlsma JA, tenBerge IJL, Bemelman FJ (2019). Fatigue, anxiety, depression and qualityoflife in kidneytrans plant recipients, haemodialysis patients, patients with a haematologicalmalignancy and healthy controls, Nephrology Dialysis Transplantation, 34(5):833-838,

VoskampPWM, van Diepen M, Evans M, Caskey FJ, Torino C, Postorino M, Szymczak M, Klinger M, Wallquist C, van de Luijtgaarden MWM, Chesnaye NC, Wanner C, Jager KJ, Dekker FWFW (2019). The impact of symptomson health-related quality of life in elderlypredialysis patients: effect and importance in the EQUAL study, Nephrology Dialysis Transplantation, 34(10):17071715, https://doi.org/10.1093/ndt/gfy167 